\title{
Pathophysiological aspects and clinical outcome of intra-anal application of isosorbide dinitrate in patients with chronic anal fissure
}

\author{
W R Schouten, J W Briel, M O Boerma, J J A Auwerda, E B Wilms, B H Graatsma
}

\begin{abstract}
Background-Relaxation of the internal anal sphincter can be achieved by local application of exogenous nitric oxide donors.

Aim-To evaluate the influence of topical application of isosorbide dinitrate (ISDN) on anal pressure, anodermal blood flow, and fissure healing.

Patients-Thirty four consecutive patients (male/female: 18/16; mean age (SEM): 39 (10)) with a chronic anal fissure were studied.
\end{abstract}

Methods-All patients were treated for at least six weeks or a maximum period of 12 weeks. Before treatment and at three and six weeks 22 patients underwent conventional anal manometry and laser Doppler flowmetry of the anoderm.

Results-Within 10 days the fissure related pain was resolved in all patients. At six, nine, and 12 weeks the anal fissure was completely healed in 14,22 , and 30 patients respectively. At three and six weeks manometry was performed at least one hour after the last application of ISDN. These recordings showed a reduction of the maximum resting anal pressure (mean (SD), pretreatment 111 (26) $\mathrm{mm}$ Hg; three weeks 86 (19); six weeks 96 (27), $p<0.001)$. Simultaneous recordings of anodermal blood flow showed a significant increase of flow (pretreatment $0.53(0.17)$; three weeks $0.80(0 \cdot 16)$; six weeks 0.76 $(0.31), p<0.005)$. The mean (SEM) duration of follow up after successful outcome was 11 (5) months. Within this period fissure relapsed in two of 30 patients $(7 \%)$, eight and 10 weeks after treatment had been stopped.

Conclusions-Local application of ISDN reduces anal pressure and improves anodermal blood flow. This dual effect results in a fissure healing rate of $88 \%$ at 12 weeks. This new and simple treatment modality seems to be an attractive alternative for the current available surgical procedures.

(Gut 1996; 39: 465-469)

Keywords: anal fissure, anal pressure, anodermal blood flow, chemical sphincterotomy.

In a previous study, aimed at evaluating the relation between anal pressure and anodermal blood flow, the blood supply of the anoderm at the posterior midline was found to be significantly lower than at the other sides of the anal canal. ${ }^{1}$ Furthermore, a significant relation between anal pressure and anodermal blood flow was found at the posterior midline. The higher the pressure, the lower the blood flow. ${ }^{1}$ These findings are supported by the results of an angiographic postmortem study, in which the small branches of both inferior rectal arteries passing through the internal anal sphincter had no, or only minimal contact at the posterior commissure in $85 \%$ of the patients. $^{2}$ Reduction of anal pressure by sphincterotomy improved anodermal blood flow at the posterior midline, which finally resulted in fissure healing. ${ }^{3}$ Based on these and other studies it has been suggested that chronic anal fissures are ischaemic in origin. Although both anal dilatation and lateral internal sphincterotomy give excellent results, their efficacy should be weighted against the possible risk of subsequent disturbances of continence. To prevent permanent sphincter defects several authors tend to a more conservative approach. A non-surgical approach, characterised by chemical and reversible reduction of anal pressure, is the ideal one. Recently, nitric oxide (NO) has been identified as the chemical messenger of the intrinsic non-adrenergic, non-cholinergic pathway, mediating relaxation of the internal anal sphincter. ${ }^{4}$ It has been shown that local application of exogenous NO donors, such as glyceryl trinitrate, reduces anal pressure..$^{56}$ Therefore, it seems likely that these increase the microcirculation at the fissure site, finally resulting in fissure healing. In this study isosorbide dinitrate (ISDN) was used as an exogenous NO donor.

\section{Methods}

This study was approved by the medical ethical committee of the University Hospital, Rotterdam. Informed consent was obtained from all patients. Between June 1994 and December 199534 consecutive patients with chronic anal fissure were studied. This group consisted of 16 women and 18 men with a mean age of 39 (SD 10) years. All patients had a history of anal fissure for more than three months. Their fissures showed features of chronicity, such as exposure of the internal anal sphincter, induration of the fissure edges, development of a large sentinel pile and hypertrophied anal papilla. Twenty nine fissures were located at the posterior midline, four at 
the anterior midline, and one both anteriorly and posteriorly. In six patients ambulant anal manometry, as described by Auwerda and Schouten, ${ }^{7}$ was performed before treatment. Because sleep was associated with a reduction of anal pressure to $39 \%$ of ambulatory values, we decided to apply the ISDN ointment only during the day. All patients were instructed to apply $1 \mathrm{~g}$ ointment to the anoderm every three hours with the index finger. In 11 patients prolonged anal manometry was performed for at least one hour, directly after the first application of ISDN ointment. All patients were interviewed and examined three and six weeks after starting treatment, and every three weeks thereafter until the fissure had healed or until two weeks of treatment had passed. Before treatment and three and six weeks after starting treatment 22 patients underwent conventional anal manometry and laser Doppler flowmetry of the anoderm. Both were performed at least one hour after the last ISDN application.

\section{Isosorbide dinitrate ointment}

A composite of ISDN in lactose (Sigma Chemical Co, LA, USA) was incorporated in an ointment base consisting of $10 \%$ lanoline and $10 \%$ liquid paraffin in white soft paraffin wax. In ISDN treatment of coronary artery disease the daily dose varies between 30 and $160 \mathrm{mg}$. The bioavailability of ISDN is about $29 \%$ after oral administration. ${ }^{8}$ Therefore, we assumed that intra-anal application of $50 \mathrm{mg}$ (10 mg five times a day) ISDN would be tolerable. For application to the anoderm, $1 \mathrm{~g}$ ointment base seemed suitable. Therefore, we incorporated $10 \mathrm{mg}$ ISDN in $1 \mathrm{~g}$ ointment base $(1 \%)$. It is well known that ISDN is metabolised to isosorbide mononitrate (ISMN). This active metabolite has a longterm effect, whereas the short-term effect of local application is attributed to ISDN itself.

\section{Laser Doppler flowmetry}

Microvascular perfusion of the anoderm was assessed by laser Doppler flowmetry with a Periflux PF2B laser Doppler flowmeter (Perimed, Stockholm, Sweden). This instrument contains a low power helium-neon laser, which generates a narrow beam of monochromatic light. For the purpose of this study a special angled probe (PF 306, Perimed, Stockholm, Sweden) was developed with an external diameter of $2.3 \mathrm{~mm}$. In this probe three optical fibres were incorporated, one for the transmission of the laser light (wavelength 632.8 $\mathrm{nm}$ ) and two for the transport of the reflected light. Before each measurement the room temperature was adjusted to $22^{\circ} \mathrm{C}$. All recordings were performed by one investigator (WRS). The measurements were obtained without bowel preparation and with the patient in the left lateral position with hips and knees flexed at $90^{\circ}$. After introduction into the anal canal the probe head was applied to the fissure site. The blood flow was measured for four minutes. To prevent occlusion of the micro- vessels, pressure to the underlying anoderm was avoided. During each measurement the probe was held by hand. The back scattered light was converted by photodetectors into electronic signals. After extraction of the Doppler shifted components and suppression of interfering frequencies a cell motion correlated signal was produced. The signal represents the flux, which is defined as the number of blood cells moving in the measured volume multiplied by the mean velocity of these cells. The flux is expressed in volts.

\section{Anal manometry}

Measurements were obtained without bowel preparation and with the patient in the left lateral position with the hips and knees flexed at $90^{\circ}$. Anal resting pressures were measured with a micro tip pressure transducer (Millar Instruments Inc, Houston, TX, USA) with an outside diameter of $1.7 \mathrm{~mm}$. In each patient the catheter was introduced into the rectum until rectal pressure was recorded. Then the probe was pulled out manually. This manoeuvre was repeated three times. The mean value of the maximum resting anal pressure (MRAP) was determined for each patient.

\section{Statistical analysis}

Measurements before treatment were compared by paired $t$ tests with those obtained at three and six weeks after starting treatment. A $p$ value $<0.05$ was considered significant. All results are reported as means (SD).

\section{Results}

All patients experienced mild, transient headache during the first two days. No patient had to stop treatment because of this. Within 10 days the fissure related pain was resolved in all patients. At six, nine, and 12 weeks anal fissure was completely healed in $14(41 \%), 22(65 \%)$ and $30(88 \%)$ patients respectively.

Before treatment MRAP was 111 (26) $\mathrm{mm}$ $\mathrm{Hg}$. The flux at the fissure site was $0.53(0.17)$ volts. Directly after ISDN application prolonged manometry was performed in 11 patients. In this subgroup MRAP started to decrease within five minutes. The mean pressure drop was 49 $(10) \%$. The pressure was reduced during a mean period of 41 (10) minutes (Fig 1). Three and six weeks after starting treatment MRAP was respectively 86 (19) $\mathrm{mm} \mathrm{Hg}$ and 96 (27) $\mathrm{mm} \mathrm{Hg}$. At the same time, the flux, measured at the original fissure site, was $0.80(0 \cdot 16)$ volts and $0.76(0.31)$ volts, respectively. These data indicate a significant pressure drop during treatment, which was associated with a significant increase of anodermal blood flow $(p<0.001$ and $\mathrm{p}<0.005$ respectively (Fig 2 )).

The mean (SEM) duration of follow up after successful outcome was 11 (5) months. Within this period fissure relapsed in two of 30 patients $(7 \%)$ respectively eight and 10 weeks after treatment had been stopped.

The patients with a persistent fissure after 12 weeks of treatment underwent lateral internal 


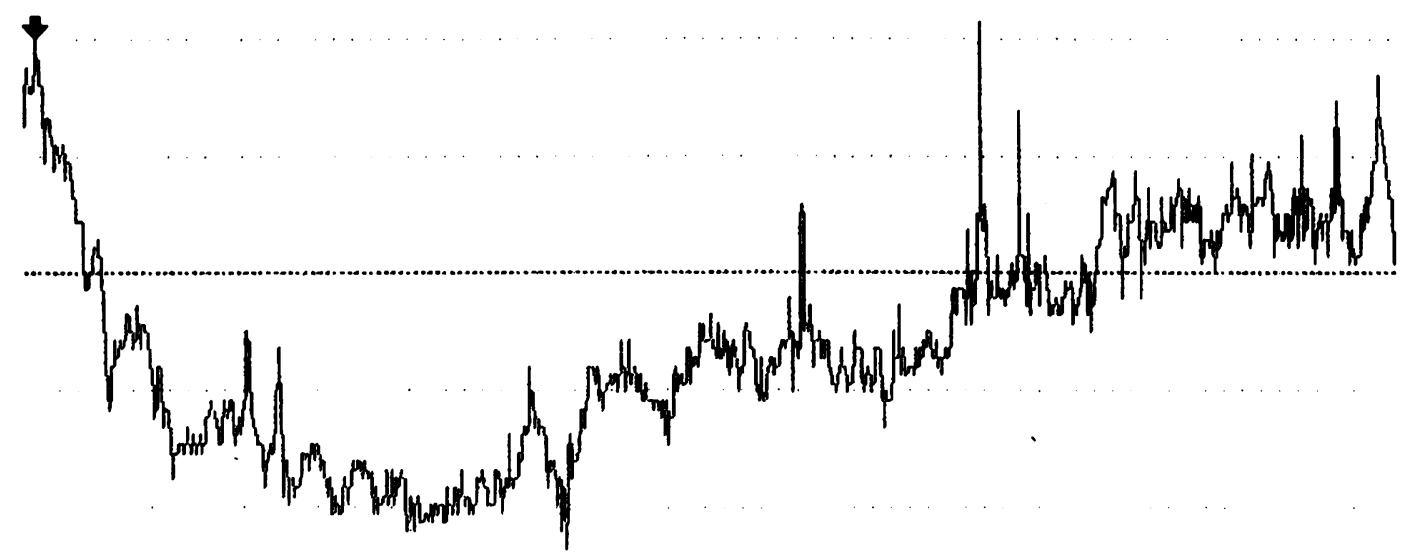

\begin{tabular}{|c|c|c|c|c|c|c|c|}
\hline \multicolumn{5}{|c|}{0} & \multicolumn{3}{|c|}{0} \\
\hline & 7 & T) & $T$ & 10.10 .00 & T. & T12.20.0 & T19.0 \\
\hline
\end{tabular}

Figure 1: Example of anal pressure reduction, starting within five minutes after ISDN application (arrow).

sphincterotomy $(n=2)$ or fissure excision followed by anoplasty $(n=2)$.

\section{Discussion}

There is growing evidence that chronic anal fissure is ischaemic in origin. In a postmortem angiographic study it was shown that the small branches of the inferior rectal artery pass through the internal anal sphincter in a direction perpendicular to the muscle fibre course. In addition, the branches of both arteries have no or only minimal contact at the posterior midline. ${ }^{2}$ These data suggest that, by nature, the posterior commissure of the anal canal is less well perfused than the other segments of the anoderm. Recently this assumption has been confirmed by assessment of anodermal blood supply with laser Doppler flowmetry. ${ }^{1}$ At the beginning of arterioles the intraluminal pressure drops to about $85 \mathrm{~mm}$ $\mathrm{Hg}$. Normal anal canal resting pressures are

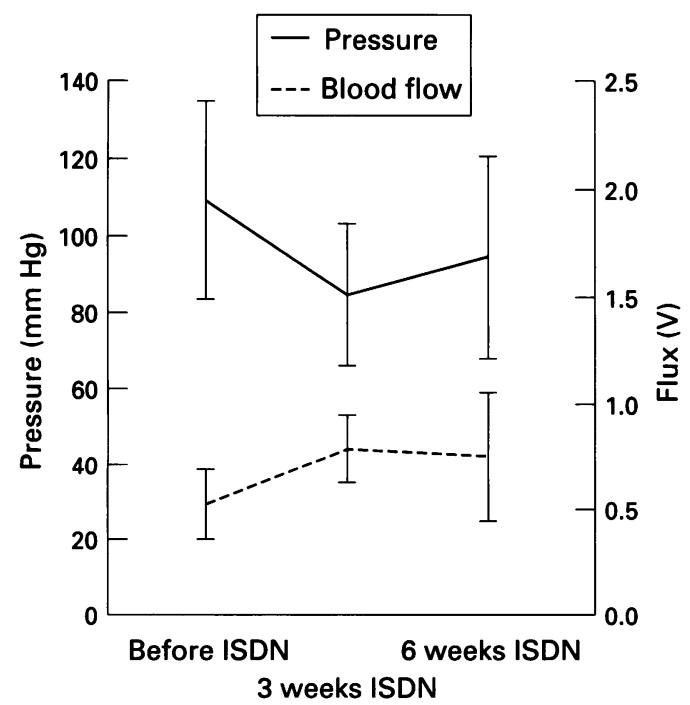

Figure 2: Maximum resting anal pressure and anodermal blood flow before and during treatment with ISDN. within this range. Patients with anal fissure have significantly higher pressures, exceeding the intraluminal pressure of arterioles. Therefore, it seems likely that increased activity of the internal anal sphincter further decreases the anodermal blood supply, especially at the posterior midline. In patients with an acute anal fissure the partial oxygen pressure in the anoderm is reduced, particularly in the region of the fissure. ${ }^{9}$ Impairment of the microcirculation at the fissure site has been confirmed with laser Doppler flowmetry. ${ }^{3}$ Furthermore, it has been shown that reduction of anal pressure by lateral internal sphincterotomy allows sufficient resumption of anodermal blood flow, which subsequently results in fissure healing. ${ }^{3}$ All these findings provide evidence for the ischaemic nature of anal fissures. Reduction of anal resting pressure, either by anal dilatation or by lateral internal sphincterotomy, is the most important step in the treatment of chronic anal fissure. Although both procedures give excellent results, their efficacy should be weighted against the possible risk of subsequent faecal incontinence. To prevent permanent sphincter defects and subsequent disturbances of continence, a nonsurgical approach, characterised by chemical and reversible reduction of anal pressure, would be ideal. In 1987 Jonard and Essamri showed that anal resting pressure decreases shortly after oral administration of $60 \mathrm{mg}$ diltiazem (mean pressure drop $20 \%$ ). Based on this finding both authors advocated treatment with this calcium channel blocker in patients with proctalgia fugax. ${ }^{10}$ Recently, NO has been identified as the chemical messenger of the intrinsic non-adrenergic, non-cholinergic pathway mediating relaxation of the internal anal sphincter. ${ }^{41-14}$ It has been shown that the axons of nerve cell bodies producing NO, located in the distal part of the rectum, descend into the anal canal where they ramify into and throughout the internal anal sphincter. ${ }^{15}$ Based on these findings it seems likely that exogenous 
NO donors such as glycerin trinitrate and ISDN might reduce anal pressure by relaxation of the internal anal sphincter. In 1990 L'Hopital and coworkers showed that anal pressure decreased for a short time by a mean of $50 \%$ after sublingual administration of glyceryl trinitrate spray. ${ }^{16}$ Although the action is more prolonged after intra-anal application $^{5617}$ the variability in the duration of action indicates different bioavailability in different subjects. In 1992 Chen et al reported a healing rate of $84 \%$ after local application of solcoderm in patients with an acute anal fissure. ${ }^{18}$ Solcoderm is an aqueous solution of organic and inorganic acids, copper ions, and nitrates. According to the authors this solution causes 'local ischaemia which contributes to the formation of granulation tissue'. In our opinion, it is more likely that the nitrates within solcoderm act as exogenous NO donors resulting in relaxation of the internal anal sphincter, which increases the microcirculation at the fissure site. In a recent study, conducted by Watson et al, anal fissures were treated with topical $0.2 \%$ glyceryl trinitrate on a twice daily regimen. An adequate pressure reduction $(30 \%)$ was found in four of 13 patients. At six weeks the fissure healing rate was only $33 \%$. Based on these rather disappointing results, the authors suggested that patients with anal fissure may show a reduced sensitivity to topical glyceryl trinitrate in lowering anal pressure. ${ }^{19}$ More promising data have been reported by Lund and coworkers. Twenty one consecutive patients with chronic anal fissure were recruited for the same treatment regimen. At six weeks the healing rate of fissures was $86 \%{ }^{20}$ Similar results have been reported by Gorfine. ${ }^{2122}$ This study shows that the fissure related pain was resolved in all patients within 10 days, despite the fact that none of the fissures was healed at that time. At six, nine, and 12 weeks the fissure healing rate was respectively $41 \%, 65 \%$, and $88 \%$. The patients who remained with a persistent fissure despite three months of treatment were, however, pain free. The pressure reduction at three and six weeks was associated with a significant increase of anodermal blood flow at the fissure site. As both anal manometry and laser Doppler flowmetry were performed at least one hour after the last application of ISDN, it seems likely that the effects of ISDN at three and six weeks is caused by its long acting metabolite ISMN.

Relaxation of the internal anal sphincter by topical ISDN probably permits sufficient resumption of the microcirculation at the fissure site, which subsequently promotes fissure healing. Both pressure reduction and improvement of anodermal blood flow underlie, in our opinion, the early pain relief. The fissure healing itself requires more time, varying between six and 12 weeks.

Recently, another therapeutic approach, using botulin toxin injections, has been described. This toxin inhibits the release of acetylcholine into the synaptic gap and is therefore a versatile tool for the weakening of striated muscles. It has been reported that botulin toxin also weakens smooth muscles in the intestinal tract. ${ }^{23}$ Jost and Schimrigk used this toxin to treat 12 patients with chronic anal fissure, by injection into the external anal sphincter on both lateral sides. Short-term follow up at six months showed that the fissure was healed in 10 patients. ${ }^{24}$ Gui and coworkers used another technique, injecting botulin toxin into the internal anal sphincter on both lateral sides as well as posteriorly at the fissure site. One month after treatment anal resting pressure was reduced by $24 \%$. After short-term follow up the healing rate was $84 \%$. Despite these promising results it seems unlikely that this new therapeutic approach will be used on a large scale because of the high costs of botulin toxin injections. Adverse side effects, such as temporary incontinence and perianal thrombosis, have been reported, particularly in female patients with relatively normal anal pressure. ${ }^{25}$ Glyceryl trinitrate and ISDN are much cheaper than botulin. The only side effect reported so far is mild transient headache. Based on the results of this study we consider local application of exogenous NO donors such as ISDN a viable and attractive alternative for most patients with chronic anal fissure.

The abstract form of this manuscript was published in Gut 1995; 36 (suppl 1): A16.

1 Schouten WR, Briel JW, Auwerda JJA. Relationship between anal pressure and anodermal blood flow: the vascular pathogenesis of anal fissures. Dis Colon Rectum 1994; 37: 664-9.

2 Klosterhalfen B, Vogel P, Rixen H, Mittermayer C. Topography of the inferior rectal artery: a possible cause of chronic, primary anal fissure. Dis Colon Rectum 1989; 32: 43-52.

3 Schouten WR, Briel JW, Auwerda JJA, de Graaf EJR. The ischaemic nature of anal fissure. Br $\mathcal{f}$ Surg 1996; 83: 63-5.

4 Rattan S, Sarkar A, Chakder S. Nitric oxide pathway in rectoanal inhibitory reflex of opossum internal anal sphincter. Gastroenterology 1992; 103: 43-50.

5 Guillemot F, Leroi H,Lone YC, Rousseau CG, Lamblin MD, Cortot A. Action of in situ nitroglycerine on upper canal pressure of patients with terminal constipation. A pilot study. Dis Colon Rectum 1993; 36: 372-6.

6 Loder PB, Kamm M, Nicholls RJ, Phillips RKS. Reversible chemical sphincterotomy by local application of glyceryl trinitrate. Br ₹ Surg 1994; 81: 1386-9.

7 Auwerda JJA, Schouten WR. New device for adequate fixation of recording instruments in ambulant anorectal fixation of recording instruments in ambulant
manometry. Dis Colon Rectum 1994; 37: 383-5.

8 Straehl P, Galeazzi RL. Isosorbide dinitrate bioavailability, kinetics, and metabolism. Clin Pharmacol Ther 1985; 38: kinetics,

9 Klug W, Knoch HG. Comparing dilator efficacy in the treatment of acute anal fissures. Coloproctology 1993; 1: 22-8

10 Jonard P, Essamri B. Diltiazem and internal anal sphincter. Lancet 1987; 1: 754.

11 Tottrup A, Glavind EB, Swane D. Involvement of the L-arginine-nitric oxide pathway in internal anal sphincter relaxation. Gastroenterology 1992; 102: 409-15.

12 Chakder S, Rattan S. Release of nitric oxide by activation of nonadrenergic noncholinergic neurons of internal anal of nonadrenergic noncholinergic neurons

13 Rattan S, Chakder S. Role of nitric oxide as a mediator of internal anal sphincter relaxation. Am $\mathfrak{f}$ Physiol 1992; 262: internal an

14 O'Kelly T, Brading A, Mortensen N. Nerve mediated relaxation of the human internal anal sphincter: the role of nitric oxide. Gut 1993; 34: 689-93.

15 O'Kelly TJ, Davies JR, Brading AF, McC Mortensen NJ. Distribution of nitric oxide synthase containing neurons in the rectal myenteric plexus and anal canal. Dis Colon Rectum 1994; 37: 350-7.

16 L'Hopital F, Michelland O, Lunaud B, Bommelaere G Constipation et hypertonie du sphincter interne de l'anus: réponse sphinctérienne à l'administration sub-linguale de $0.40 \mathrm{mg}$ de Natispray. Gastroentérol Clin Biol 1990; 14: 268.

17 Guillemot F, Lone YC, Leroi H, Lamblin MD, Cortot A. Nitroglycerin in situ reduces upper canal pressure. Dig Dis Sci 1992; 37: 155.

18 Chen J, Michowitz M, Bawnik JB. Solcoderm as alternative conservative treatment for acute anal fissure: a controlled clinical study. Am Surg 1992; 58: 705-9. 
19 Watson SJ, Kamm MA, Nicholls RJ, Phillips RKS. Glyceryl trinitrate and anal fissure: resistance to endogenous nitric oxide and tachyphylaxis. Dis Colon Rectum 1995; 38: P29.

20 Lund JN, Armitage NC, Scholefield JH. The use of glyceryl trinitrate in the treatment of anal fissure: results of a pilot study. Gut 1995; 37 (suppl 2): A5

21 Gorfine SR. Treatment of benign anal disease with topical nitroglycerin. Dis Colon Rectum 1995; 38: 453-7.
22 Gorfine SR. Topical nitroglycerin therapy for anal fissures and ulcers. N Engl $\mathcal{F}$ Med 1995; 333: 1156-7.

23 Pasricha PJ, Ravich WJ, Kalloo AN. Botulinum toxin for achalasia. Lancet 1993; 341: 244-5.

24 Jost WH, Schimrigk K. Therapy of anal fissure using botulin toxin. Dis Colon Rectum 1994; 37: 1321-4.

25 Jost WH, Schanne S, Mlitz H. Perianal thrombosis following injection therapy into the external anal sphincter using
botulin toxin. Dis Colon Rectum 1995; 38: 781. 